\title{
Effects of Soybean Sauce and Pre-rigor Muscle on Physicochemical Properties of Frozen Hanwoo Patties
}

\author{
Hyun-Wook Kim¹, Ji-Hun Choi ${ }^{1,2}$, Yun-Sang Choi ${ }^{1,2}$, Doo-Jeong Han ${ }^{1}$, Hack-Youn Kim¹, Mi-Ai Lee ${ }^{1,3}$, \\ Si-Young Kim ${ }^{1}$, and Cheon-Jei Kim ${ }^{1,2 *}$ \\ ${ }^{1}$ Department of Food Science and Biotechnology of Animal Resources, Konkuk University, Seoul 143-701, Korea \\ ${ }^{2}$ Research Institute for Meat Science and Culture, Konkuk University, Seoul 143-701, Korea \\ ${ }^{3}$ World Institue of Kimchi, An Annex of Korea Food Research Institute, Seongnam 463-746, Korea
}

\begin{abstract}
In this study, we evaluated the physicochemical and sensorial properties of frozen Hanwoo beef patties prepared from prerigor and post-rigor muscle with soybean sauce or sodium chloride. The $\mathrm{pH}$ of the soybean sauce treatments was lower than the sodium chloride treatments $(p<0.05)$; however, the Hanwoo patty prepared from pre-rigor muscle with soybean sauce had a lower cooking loss and smaller diameter than the Hanwoo patty prepared under the same conditions from post-rigor muscle $(p<0.05)$. The addition of the soybean sauce inhibited lipid oxidation due to the antioxidative materials in soybean sauce such as melanoidin. The hardness of patties prepared from pre-rigor treatment was lower relative to those prepared from post-rigor muscle $(p<0.05)$; however, there was no significant difference between springiness, cohesiveness, and chewiness $(p>0.05)$. In the sensory evaluation, patties prepared from pre-rigor muscle with soybean sauce had a significantly high score in all traits $(p<0.05)$; thus, pre-rigor muscle with soybean had the highest overall acceptability. Furthermore, the addition of soybean sauce to pre-rigor muscle produced similar effects as those observed for the addition of sodium chloride in regards to psychochemical properties. Moreover, meat products produced from pre-rigor muscle will have better antioxidative and sensorial properties.
\end{abstract}

Key words: Hanwoo, hot-boning, pre-rigor, soybean sauce, beef patty

\section{Introduction}

Pre-rigor muscles, which are muscles immediately removed from a post-slaughter carcass, were demonstrated to have several economical advantages and superior processing qualities in many countries. These benefits can be summarized as follows: 1) The economical advantages include a reduction in the need for refrigerator facilities and/or frugality of labor and transport costs (Pisula and Tyburcy, 1996), and 2) pre-rigor muscle have a higher level of salt-soluble proteins, emulsifying capacity (Jones et al., 1986), and water holding capacity (Bernthal et al., 1989; Plimpton et al., 1991) due to the higher $\mathrm{pH}$ value and ATP (adenosine tri-phosphate) concentration, all of which are beneficial processing properties.

Unfortunately, these beneficial properties decrease with

*Corresponding author: Cheon Jei Kim, Department of Food Science and Biotechnology of Animal Resources, Konkuk University, Seoul 143-701, Korea. Tel: 82-2-450-3684, Fax: 82-2-444-6695, E-mail: kimcj@konkuk.ac.kr the elapsed time after the slaughter because pre-rigor muscle will eventually convert to the post-rigor phase due to biochemical reactions such as the formation of lactic acid (by glycolysis in anaerobic condition) and depletion of ATP (Hamm, 1977; Pisula and Tyburcy, 1996). Furthermore, inappropriate or postponed processing of prerigor muscle will result in the formation of meat with substandard qualities due to cold-shortening, thaw rigor, as well as normal rigor (Lawrie, 1998). Many researchers have attempted to develop methods to maintain the beneficial processing properties of pre-rigor muscle, especially in regards to retaining the tenderness and water holding capacity. These techniques include the addition of sodium chloride, phosphate, and/or glucose (Boles and Swan, 1997; Young et al., 1988), calcium infusion (Rees et al., 2002), electrical stimulation (Jeremiah et al., 1985; Rashid et al., 1983), and curing condition (Choi et al., 2009). Hamm (1981) reported that the addition of sodium chloride (approximately 2-4\% concentration) to pre-rigor muscles inhibited actin and myosin (rigor mortis) from combining and forming actomyosin. In addition, Young 
et al. (1988) demonstrated that both sugar and salt can inhibit the $\mathrm{pH}$ from decreasing, which is caused by postmortem glycolysis.

Soybean sauce is a traditional fermented food used in Korea, together with gochojang, doenjang (fermented soybean paste), and chungkukjang, all of which contain a high salt concentration. This soybean sauce contains salt (approximately $15-20 \%$ of salt concentration), water (approximately $50-70 \%$ ), peptides, isoflavon, free sugar, and organic acids that are derived from the soybeans during the fermentation period (Jeon et al., 2002; Kim et al., 2002; Shim et al., 2008). In addition, the color properties of the soybean sauce are influenced by melanoidins, which are formed when carbonyl compounds and amino compounds combine (maillard reaction). The melanoidins in soybean sauce are important to the antioxidative properties of different types of food (Choi et al., 1990). Moon and Cheigh (1986) demonstrated that soybean sauce in cooked beef plays an important role as an antioxidant. If salt in soybean sauce (an aspect of meat product processing) has a similar effect as the addition of sodium chloride, it may be possible to produce superior meat products by adding soybean sauce to pre-rigor muscle.

Therefore, we investigated the physicochemical properties and quality characteristics of frozen Hanwoo patties prepared from pre-rigor or post-rigor beef muscles with soybean sauce or sodium chloride at identical salt concentration.

\section{Materials and Methods}

\section{Patty preparation}

Twelve Hanwoo cows (24 mon of age; live weights: $774.2 \mathrm{~kg}$; slaughter weights: $470.0 \mathrm{~kg}$ ) were slaughtered at a local municipal slaughterhouse. After splitting and bleeding, the carcasses were transferred to the cutting room. Semimembranosus muscles (SM) were removed immediately, and trimmed of visible fat and connective tissue. SMs were placed in polyethylene bags and transported to the Meat Science laboratory at Konkuk University, Korea. SMs were initially ground through an $8 \mathrm{~mm}$ plate (PM-100, Mainca, Spain) within $1 \mathrm{~h}$ post-mortem, and then randomly assigned to either a two phase sample of pre-rigor and post-rigor muscles. Half of the SM was used immediately as material for pre-rigor treatments and the other half meat was used after being stored in polyethylene bags at $4^{\circ} \mathrm{C}$ for $48 \mathrm{~h}$ as material for post-rigor treatments. Commercial soybean sauce (Fermented soybean sauce, Sempio Foods Co., Korea) was purchased from the local market. Soybean sauce showed $\mathrm{pH} 4.8$ and $16 \%$ salt concentration. Soybean sauce solution and sodium chloride solution, which were diluted with ice water for adding same salt and water contents, were made at $2 \%$ salt concentration and these solutions were added into pre- and post-rigor ground Hanwoo muscles. All samples were composed by $80 \%$ raw meat, $20 \%$ water, and $2 \%$ total salt concentration (Table 1).

All samples were mixed by hand for $5 \mathrm{~min}$, before the patties were formed, the batches were held at $4^{\circ} \mathrm{C}$ for 12 h. The each sample were processed into $100 \pm 1 \mathrm{~g}$ patties with $100 \mathrm{~mm}$ in diameter and $15 \mathrm{~mm}$ in thickness using patty presses (Small round press, Spikomat Ltd., UK), and the samples were packaged with Nylon/PE film, and stored at $-20^{\circ} \mathrm{C}$ for 3 mon.

\section{Thawing and cooking methods}

The frozen Hanwoo patties were thawed in the $4^{\circ} \mathrm{C}$ refrigerator until the core temperature of patties were reached at $4 \pm 1^{\circ} \mathrm{C}$. All thawed patties were cooked on a electric grill (CG20, Hobart, USA) at a grill surface temperature of $150^{\circ} \mathrm{C}$. The patties were cooked for $3 \mathrm{~min}$ on one side and for $3 \mathrm{~min}$ on the opposite side, and thereafter flipped over every 2 min until the targeted core temperature reached at $71^{\circ} \mathrm{C}$. All temperature changes were monitored with a digital thermometer (Tes-1305, Tes Electrical Corp., Taiwan) equipped with a data logger (RS-232, Tes Electrical Corp., Taiwan) by inserting an iron constantan thermocouple. The cooked patties were cooled down to $4^{\circ} \mathrm{C}$, and then analyzed rapidly.

\section{pH}

The $\mathrm{pH}$ sample was determined with a $\mathrm{pH}$ meter (Model 340 , Mettler-Toledo $\mathrm{GmbH}$, Switzerland). The $\mathrm{pH}$ values

Table 1. Formulation of Hanwoo patties

\begin{tabular}{lcccc}
\hline \hline \multirow{2}{*}{ Ingredient (\%) } & \multicolumn{2}{c}{ Soybean sauce } & \multicolumn{2}{c}{ Sodium chloride } \\
\cline { 2 - 5 } & $\begin{array}{c}\text { Pre- } \\
\text { rigor }\end{array}$ & $\begin{array}{c}\text { Post- } \\
\text { rigor }\end{array}$ & $\begin{array}{c}\text { Pre- } \\
\text { rigor }\end{array}$ & $\begin{array}{c}\text { Post- } \\
\text { rigor }\end{array}$ \\
\hline Pre-rigor Hanwoo muscle & 80 & - & 80 & - \\
Post-rigor Hanwoo muscle & - & 80 & - & 80 \\
Soybean sauce solution ${ }^{1)}$ & 20 & 20 & - & - \\
Sodium chloride solution & - & - & 20 & 20 \\
\hline \multicolumn{1}{c}{ Total } & 100 & 100 & 100 & 100 \\
\hline Total salt concentration & 2.0 & 2.0 & 2.0 & 2.0 \\
\hline
\end{tabular}

All values are mean \pm SD.

${ }^{1)}$ Soybean sauce solution: liquid soybean sauce diluted by ice water

${ }^{\mathrm{A}-\mathrm{C}}$ Means in the same row with different letters are significantly different $(p<0.05)$. 
of raw and cooked Hanwoo patties were measured by blending a $5 \mathrm{~g}$ sample with $20 \mathrm{~mL}$ distilled water for $60 \mathrm{~s}$ in a homogenizer (Ultra-Turrax SK15, Janke \& Kunkel, Germany).

\section{Instrumental color evaluations}

The instrumental color analysis of raw and cooked Hanwoo patties was conducted. Color measurements were taken with colorimeter (Chroma meter CR-210, Minolta, Japan; illuminate $C$, calibrated with white standard plate CIE $L^{*}=97.83$, CIE $a^{*}=-0.43$, CIE $\left.b^{*}=+1.98\right)$, consisted of an $8 \mathrm{~mm}$ diameter measuring area and a $50 \mathrm{~mm}$ diameter illumination area. Color values (CIE L ${ }^{*}, a^{*}$, and $b^{*}$ ) were measured on the surface of samples and results were taken in triplicate for each sample.

\section{Cooking rate}

The initial core temperature of the patties was measured, and the patties were cooked the final core temperature reached at $71^{\circ} \mathrm{C}$. Also, the average cooking times of the patties were measured. The cooking rates were calculated using the following expression.

$$
\begin{aligned}
& \text { Cooking rate }\left({ }^{\circ} \mathrm{C} / \mathrm{min}\right) \\
& =\left(\text { final core temperature }\left({ }^{\circ} \mathrm{C}\right)\right. \\
& \left.\quad-\text { initial core temperature }\left({ }^{\circ} \mathrm{C}\right)\right) \\
& \quad \text { / cooking time }(\min )
\end{aligned}
$$

\section{Cooking loss}

All patties were weighted before cooking, and were cooked until the core temperature reached at $71^{\circ} \mathrm{C}$. After cooling at room temperature for $1 \mathrm{~h}$, cooked Hanwoo patties were weighed and a percentage cooking loss was calculated from the weights.

$$
\begin{aligned}
& \text { Cooking loss }(\%) \\
& =((\text { weight of patty before cooking }(\mathrm{g}) \\
& \quad-\text { weight of after cooking }(\mathrm{g})) \\
& \\
& \text { /weight of patty before cooking }(\mathrm{g})) \times 100
\end{aligned}
$$

\section{Reduction in diameter}

To measure the diameter of the same locations before and after a cooking, two points per patty were marked. After each patty was cooked, it was cooled down at room temperature. The diameter of the raw and cooked patties was recorded using Vernier calipers (530-122, Mitutoyo, Japan) and calculated using the following expression.

$$
\begin{aligned}
& \text { Reduction in diameter }(\%) \\
& =((\text { diameter of raw patty }(\mathrm{cm}) \\
& \quad-\text { diameter of cooked patty }(\mathrm{cm})) \\
& \quad / \text { diameter of raw patty }(\mathrm{cm})) \times 100
\end{aligned}
$$

\section{2-Thiobarbituric acid (TBA) values}

Lipid oxidation was assessed in triplicate by the 2thiobarbituric acid (TBA) method of Tarladgis et al. (1960) with minor modifications. A $10 \mathrm{~g}$ sample was blended with $50 \mathrm{~mL}$ distilled water for 2 min and then transferred to a distillation tube. The cup used for blending was washed with an additional $47.5 \mathrm{~mL}$ of distilled water, which was added to the same distillation flask with $2.5 \mathrm{~mL} 4 \mathrm{~N} \mathrm{HCl}$ and a few drops of an antifoam agent, silicone o/w (KMK-73, Shin-Etsu Silicone Co., Ltd., Korea). The mixture was distilled and $50 \mathrm{~mL}$ distillate was collected. $5 \mathrm{~mL}$ of $0.02 \mathrm{M}$ 2-thiobarbituric acid in $90 \%$ acetic acid (TBA reagent) was added to a vial containing $5 \mathrm{~mL}$ of the distillate and mixed well. The vials were capped and heated in a boiling water bath for 30 min to develop the chromogen and cooled to room temperature. The absorbance was measured at $538 \mathrm{~nm}$, against a blank prepared with $5 \mathrm{~mL}$ distilled water and 5 $\mathrm{mL}$ TBA-reagent, using a UV/VIS spectrophotometer (Optizen 2120 UV plus, Mecasys Co. Ltd., Korea). Thiobarbituric acid-reactive substances (TBARS) were calculated from a standard curve $(8-50 \mathrm{nmol})$ of malondialdehyde (MDA), freshly prepared by acidification of TEP (1,1,3,3-tetraethoxy propane, Sigma, UK). The TBA levels were calculated as mg MDA/kg meat.

\section{Texture profile analysis (TPA)}

The profile analysis was performed in duplicate on each Hanwoo patty. Samples were cooked as previously described (electrical grill cooking method). The cooked Hanwoo patties were cooled to at room temperature for 1 $\mathrm{h}$ to determine texture properties. The textural properties of each patty were measured by a $0.25 \varnothing$ spherical probe, set attached to a Texture Analyzer (TA-XT2i, Stable Micro System Ltd., UK). The test conditions were as follow : stroke, $20 \mathrm{~g}$; test speed, $2.0 \mathrm{~mm} / \mathrm{s}$; distance, $10.0 \mathrm{~mm}$. Data were collected and analyzed from the hardness $(\mathrm{kg})$, springiness, cohesiveness, gumminess $(\mathrm{kg})$, and chewiness $(\mathrm{kg})$ values.

\section{Sensory evaluations}

The cooked Hanwoo patties were evaluated for color, flavor, juiciness, tenderness, and overall acceptability. The cooked Hanwoo patties as previously described were 
cooled to room temperature at $25 \pm 1{ }^{\circ} \mathrm{C}$ and cut and served to the panelists in random order. The sensory evaluations were performed by the panelists under fluorescence lighting. Panelists were instructed to cleanse their palates between samples using water. The color, flavor, and overall acceptability $(1=$ extremely undesirable, $10=$ extremely desirable), tenderness $(1=$ extremely tough, $10=$ extremely tender), juiciness $(1=$ extremely dry, $10=$ extremely juicy $)$ of the cooked samples were evaluated using a 10-point descriptive scale. The panel consisted of 10 members from the department of food sciences and biotechnology of animal resources at Konkuk University in Korea.

\section{Statistical analysis}

An analysis of variance were performed on all the variables measured using the General Linear Model (GLM) procedure of the SAS statistical package (SAS Institute, Inc., 1999). Duncan's multiple range test $(p<0.05)$ was used to determine differences between treatment means.

\section{Results and Discussion}

\section{pH and color}

Table 2 presents the $\mathrm{pH}$ value and color of raw and cooked Hanwoo patties prepared from pre-rigor or postrigor muscles with soy sauce or sodium chloride. The $\mathrm{pH}$ values of raw meats were 6.67 (pre-rigor muscle) and 5.82 (post-rigor muscle), respectively. The $\mathrm{pH}$ values for all treatments decreased after the addition of soybean sauce and sodium chloride; however, owing to the low $\mathrm{pH}$ values of the soybean sauce, the soybean sauce treatment had a lower $\mathrm{pH}$ than sodium chloride treatment $(p<0.05)$. After cooking, the $\mathrm{pH}$ values under all treatments increased, which closely mirrored the results observed for the raw meat. Generally, pre-rigor muscle has been shown to have a higher $\mathrm{pH}$ value compared with that of postrigor muscle and this result was observed for all samples examined in this study $(p<0.05)$. In our study, the soybean sauce as well as sodium chloride resulted in a decrease in the $\mathrm{pH}$ value. Torres et al. (1988) reported that the addition of sodium chloride to pre-rigor muscle decreased the $\mathrm{pH}$ value. In the addition of soybean sauce, it had a lower $\mathrm{pH}$ value (4.80), Jeon et al. (2002) reported that the low $\mathrm{pH}$ value of the soybean sauce was caused by the proliferation of lactic acid bacteria during the fermentation period.

Generally, the color of slaughtered muscle changes from dark red to bright red due to the oxidation of myoglobin to oxymyoglobin on the surface of the muscle (Seideman, 1987). For the CIE L* values (lightness), we found that the type of salts and muscle rigor states did not affect the color of the raw meat at all treatment conditions ( $p>0.05)$; however, after cooking, the patties prepared from pre-rigor muscle with sodium chloride had a significantly higher lightness $(p<0.05)$. In this study, patties prepared from pre-rigor muscle with sodium chloride had the highest CIE a value (redness) in both the raw and cooked states. In the CIE $b^{*}$ values (yellowness) of cooked samples, the patties prepared from pre-rigor muscle with sodium chloride had the highest values among the all samples $(p<0.05)$. Farouk and Swan (1997) reported that lipid oxidation associated with protein denaturation influenced the lightness, Farouk and Swan (1998) also reported that changes in ionic strength due to the addition of salts did not influence the redness value of meat. However, in this study, significant differences between the addition of soybean sauce and sodium chloride were expected due to the unique color properties of soybean sauce. Andersen et al. (1990) reported that the addition of $1.0 \%$ sodium chloride to minced meat tended to increase

Table 2. The pH and instrumental color values of the raw or cooked Hanwoo patties prepared from pre- and post-rigor muscles with soybean sauce or sodium chloride

\begin{tabular}{|c|c|c|c|c|c|}
\hline \multirow{2}{*}{ Type } & \multirow{2}{*}{ Traits } & \multicolumn{2}{|c|}{ Soybean sauce } & \multicolumn{2}{|c|}{ Sodium chloride } \\
\hline & & Pre-rigor & Post-rigor & Pre-rigor & Post-rigor \\
\hline \multirow{4}{*}{ Raw } & $\mathrm{pH}$ & $5.96 \pm 0.02^{\mathrm{B}}$ & $5.62 \pm 0.02^{\mathrm{D}}$ & $6.02 \pm 0.02^{\mathrm{A}}$ & $5.68 \pm 0.03^{C}$ \\
\hline & $\mathrm{CIE} \mathrm{L}^{*}$ & $40.26 \pm 1.18$ & $39.76 \pm 2.84$ & $42.21 \pm 0.93$ & $41.86 \pm 1.33$ \\
\hline & CIE $a^{*}$ & $5.57 \pm 0.43^{\mathrm{B}}$ & $5.54 \pm 0.85^{\mathrm{B}}$ & $7.86 \pm 0.66^{\mathrm{A}}$ & $6.96 \pm 0.40^{\mathrm{AB}}$ \\
\hline & CIE b* & $4.07 \pm 0.42^{\mathrm{B}}$ & $4.31 \pm 0.73^{\mathrm{B}}$ & $4.23 \pm 0.29^{\mathrm{B}}$ & $5.29 \pm 0.55^{\mathrm{A}}$ \\
\hline \multirow{4}{*}{ Cooked } & $\mathrm{pH}$ & $6.19 \pm 0.02^{\mathrm{B}}$ & $5.89 \pm 0.03^{\mathrm{D}}$ & $6.32 \pm 0.02^{\mathrm{A}}$ & $5.94 \pm 0.03^{\mathrm{C}}$ \\
\hline & CIE L ${ }^{*}$ & $45.45 \pm 0.27^{\mathrm{C}}$ & $44.27 \pm 0.42^{\mathrm{D}}$ & $47.88 \pm 0.51^{\mathrm{A}}$ & $46.63 \pm 0.34^{\mathrm{B}}$ \\
\hline & CIE a* & $4.31 \pm 0.22^{\mathrm{C}}$ & $4.05 \pm 0.08^{\mathrm{D}}$ & $5.15 \pm 0.19^{\mathrm{A}}$ & $4.72 \pm 0.11^{\mathrm{B}}$ \\
\hline & CIE b* & $4.82 \pm 0.37^{\mathrm{A}}$ & $4.12 \pm 0.30^{\mathrm{B}}$ & $5.01 \pm 0.42^{\mathrm{A}}$ & $4.90 \pm 0.14^{\mathrm{A}}$ \\
\hline
\end{tabular}

All values are mean \pm SD.

${ }^{\text {A-D }}$ Means in the same row with different letters are significantly different $(p<0.05)$. 
discoloration. In our study, the addition of soybean sauce also did not affect the color stability of pre-rigor Hanwoo muscle.

\section{Cooking rate, cooking loss, and reduction in diam- eter}

Cross et al. (1979) reported that freezing pre-rigor muscle could potential produce thaw rigor; therefore, to prevent thaw rigor, all pre-rigor treatments had holding time of $12 \mathrm{~h}$ before freezing. The cooking rate, cooking loss, and reduction in diameter of frozen Hanwoo patties are shown in Table 3. There were no significant differences in cooking rates according to the rigor states for both soybean sauce and sodium chloride treatment $(p>0.05)$. The cooking rates for sodium chloride treatments were higher than soybean sauce treatments $(p<0.05)$. In contrast to these results, Berry et al. (1999) previously reported that hot-boned ground beef had a longer cooking time than chilled ground beef. The reason for these differences in cooking time may have been because of differences in cooking methods and handling of pre-rigor muscle. Cooking loss and reduction in diameter of frozen Hanwoo patty prepared from pre-rigor muscle with sodium chloride were the lowest among all the samples, and all samples prepared pre-rigor muscle had a lower cooking loss and reduction in diameter than those prepared with postrigor muscle $(p<0.05)$. Cooking loss is affected by the water holding capacity and extractable protein of raw meat (Plimpton et al., 1991; Trout, 1988). Bernthal et al. (1989) reported that ground beef muscle had a high water holding capacity and extractable protein content in the initial phase of post-mortem (pre-rigor state), In addition, Cross et al. (1979) noted that hot-boned ground beef had a lower cooking loss and change in diameter due to a lower water loss during cooking. For these reasons, Silva et al. (1993) suggested that the high water binding capacity of pre-rigor muscle resulted from a high $\mathrm{pH}$ and ATP content. Thus, differences in $\mathrm{pH}$ values between the prerigor and the post-rigor muscle could lead to the disparity in cooking shrinkage (Shin et al., 1999). As a result of the superior processing qualities of pre-rigor muscle, all samples prepared with pre-rigor muscle had a lower cooking loss. Jacobs and Sebranek (1980) reported similar results on frozen ground beef patties. Generally, the addition of salt leads to an increase in the water holding capacity and cooking yield due to an increase in the ionic strength (Lamkey et al., 1986). Meanwhile, in pre-rigor muscle, we found that samples prepared with pre-rigor muscle and soybean sauce had a higher cooking loss than samples prepared with post-rigor and sodium chloride. A potential reason for this result was that the soybean sauce contains other chemical entities such as amino acids and minerals (Choi et al., 2000). These additional compounds may have negatively influenced the effect of adding salt, even if soybean treatment contained the same salt concentration compared with the sodium chloride treatment. Therefore, the salting effects of soybean sauce on prerigor were slightly lower than the addition of only sodium chloride.

\section{TBA values}

The TBA values of cooked Hanwoo patties prepared from pre-rigor or post-rigor muscles and soybean sauce or sodium chloride are shown in Fig. 1. Patties prepared from pre-rigor muscle had significantly lower TBA values than those prepared from post-rigor muscle $(p<0.05)$. In addition, patties prepared from pre-rigor muscle and soybean sauce had the lowest TBA values. Generally, post-mortem muscle undergoes lipid oxidation. Drerup et al. (1981) reported that the TBA values of pre-rigor ground muscle were lower than those of post-rigor muscle. Our results are in agreement with these previous findings. Many other studies have reported that sodium chloride affected lipid oxidation due to the release of iron ions from heme pigments (Buckley et al., 1989; Lee et al., 1997). Meanwhile, Moon and Cheigh (1986) reported that the addition of soybean sauce had an obvious antioxidative effect on the lipid oxidation of beef meat, and

Table 3. Cooking rate, cooking loss, and reduction in diameter of the cooked Hanwoo patties prepared from pre- and post-rigor muscles with soybean sauce or sodium chloride

\begin{tabular}{lccccc}
\hline \hline \multirow{2}{*}{ Traits } & \multicolumn{2}{c}{ Soybean sauce } & & \multicolumn{2}{c}{ Sodium chloride } \\
\cline { 2 - 3 } \cline { 5 - 6 } & \multicolumn{1}{c}{ Pre-rigor } & Post-rigor & & \multicolumn{1}{c}{ Pre-rigor } & \multicolumn{2}{c}{ Post-rigor } \\
\hline Cooking rate $\left({ }^{\circ} \mathrm{C} /\right.$ min) & $7.75 \pm 0.78^{\mathrm{B}}$ & $7.79 \pm 0.33^{\mathrm{B}}$ & & $8.73 \pm 0.40^{\mathrm{A}}$ & $8.82 \pm 0.49^{\mathrm{A}}$ \\
Cooking loss (\%) & $17.47 \pm 0.73^{\mathrm{B}}$ & $31.85 \pm 0.79^{\mathrm{A}}$ & & $13.81 \pm 0.74^{\mathrm{C}}$ & $32.23 \pm 1.88^{\mathrm{A}}$ \\
Reduction in diameter (\%) & $16.81 \pm 0.66^{\mathrm{B}}$ & $21.30 \pm 0.98^{\mathrm{A}}$ & & $14.65 \pm 0.74^{\mathrm{C}}$ & $22.48 \pm 1.20^{\mathrm{A}}$ \\
\hline
\end{tabular}

All values are mean \pm SD.

${ }^{\mathrm{A}-\mathrm{C}}$ Means in the same row with different letters are significantly different $(p<0.05)$. 


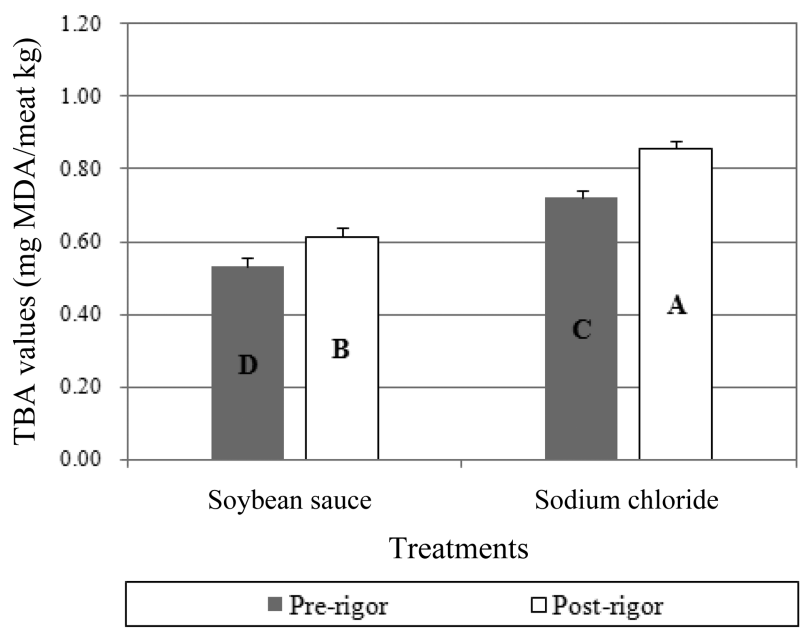

Fig. 1. The effect of soybean sauce and sodium chloride on TBA (2-thiobarbituric acid) values of the cooked Hanwoo patties prepared from pre- and post-rigor muscles with soybean sauce or sodium chloride. ${ }^{\mathrm{A}-\mathrm{D}}$ Means in the samples with different letters are significantly different $(p<0.05)$.

Jeon et al. (2002) indicated that the antioxidative properties of soybean sauce was related to melanoidin, which is formed by the maillard reaction. In this study, the reason for the lower TBA values in the soybean sauce treatments was most likely due to the presence of antioxidative compounds in the adding soybean sauce such as melanoidin, even at increased salt concentrations.

\section{Texture properties}

Table 4 compares the textures properties of cooked Hanwoo patties prepared from pre-rigor or post-rigor muscles and soybean sauce or sodium chloride. The hardness of patties prepared from post-rigor muscle was higher than those prepared from pre-rigor muscle and there was no significant difference between the addition of soybean sauce and sodium chloride $(p>0.05)$. Pisula and Tyburcy (1996) reported that there were no differences in the binding properties of restructured beef products prepared from hot-boning or cold-boning meat. Similarly, in this study, there were no significant differences of springiness, cohesiveness, and chewiness by the rigor state $(p>0.05)$. In contrast, the gumminess of patties prepared from prerigor muscle and sodium chloride was the highest $(p<$ 0.05 ). Thomas et al. (2008) noted that sausage made from hot-boned pork had a significant difference in textural properties (hardness, gumminess, and chewiness) compared with the sausage prepared from cold-boned pork meat. The quality properties of pre-rigor muscle greatly changes depending on the storage conditions and processing methods, therefore, methods to maintain the pre-rigor quality are required. The utilization of functional additives was previously shown not to improve the properties of pre-rigor muscle (Pisula and Tyburcy, 1996). For the addition of soybean sauce, the various additional compounds in the soybean sauce also did not specially influence the textural properties of the Hanwoo patty due to the decrease of ionic strength. Therefore, the effects of adding soybean sauce to frozen Hanwoo patties prepared from pre- or post-rigor muscle were generally similar to the addition of sodium chloride in regards to the textural properties excluding gumminess.

\section{Sensory properties}

The results of the sensory evaluation are shown in Table 5. The Hanwoo patty prepared from pre-rigor muscle and soybean sauce had the highest color and flavor scores among all the samples $(p<0.05)$. Under these conditions, the pre-rigor muscle had a dark red color of, which became brown after the addition of the soybean sauce. Choi et al. (2000) reported that soybean sauce could improve the flavor of meat products, which increased the sweetness (by a free sugar), sourness (by organic acids), and savory flavor (by nitrogenous compounds) in addition the saltiness, and thus the addition of soybean sauce could contribute to increasing the overall flavor of meat. All patties prepared using pre-rigor muscle had a

Table 4. Comparisons on texture properties of the cooked Hanwoo patties prepared from pre- and post-rigor muscles with soybean sauce or sodium chloride

\begin{tabular}{|c|c|c|c|c|}
\hline \multirow{2}{*}{ Traits } & \multicolumn{2}{|c|}{ Soybean sauce } & \multicolumn{2}{|c|}{ Sodium chloride } \\
\hline & Pre-rigor & Post-rigor & Pre-rigor & Post-rigor \\
\hline Hardness (kg) & $1.16 \pm 0.08^{\mathrm{B}}$ & $1.39 \pm 0.06^{\mathrm{A}}$ & $1.11 \pm 0.08^{\mathrm{B}}$ & $1.30 \pm 0.11^{\mathrm{A}}$ \\
\hline Springiness & $0.79 \pm 0.04$ & $0.77 \pm 0.05$ & $0.77 \pm 0.03$ & $0.79 \pm 0.04$ \\
\hline Cohesiveness & $0.55 \pm 0.03$ & $0.56 \pm 0.03$ & $0.54 \pm 0.03$ & $0.53 \pm 0.02$ \\
\hline Gumminess (kg) & $0.63 \pm 0.05^{\mathrm{BC}}$ & $0.72 \pm 0.08^{\mathrm{AB}}$ & $0.62 \pm 0.10^{\mathrm{C}}$ & $0.75 \pm 0.10^{\mathrm{A}}$ \\
\hline Chewiness (kg) & $0.48 \pm 0.06$ & $0.53 \pm 0.08$ & $0.48 \pm 0.04$ & $0.53 \pm 0.10$ \\
\hline
\end{tabular}

All values are mean \pm SD.

${ }^{\text {A-C }}$ Means in the same row with different letters are significantly different $(p<0.05)$. 
Table 5. Comparisons on sensory properties of the cooked Hanwoo patties prepared from pre- and post-rigor muscles with soybean sauce or sodium chloride

\begin{tabular}{lccccc}
\hline \hline \multirow{2}{*}{ Traits } & \multicolumn{2}{c}{ Soybean sauce } & & \multicolumn{2}{c}{ Sodium chloride } \\
\cline { 2 - 3 } \cline { 5 - 6 } & Pre-rigor & Post-rigor & & Pre-rigor & Post-rigor \\
\hline Color & $8.40 \pm 0.22^{\mathrm{A}}$ & $7.90 \pm 0.23^{\mathrm{B}}$ & & $7.80 \pm 0.17^{\mathrm{B}}$ & $7.80 \pm 0.27^{\mathrm{B}}$ \\
Flavor & $8.30 \pm 0.32^{\mathrm{A}}$ & $8.10 \pm 0.27^{\mathrm{B}}$ & & $7.00 \pm 0.47^{\mathrm{C}}$ & $7.60 \pm 0.26^{\mathrm{BC}}$ \\
Tenderness & $8.10 \pm 0.18^{\mathrm{A}}$ & $7.60 \pm 0.24^{\mathrm{B}}$ & & $8.20 \pm 0.59^{\mathrm{A}}$ & $7.70 \pm 0.14^{\mathrm{B}}$ \\
Juiciness & $8.20 \pm 0.23^{\mathrm{A}}$ & $7.52 \pm 0.28^{\mathrm{B}}$ & & $8.30 \pm 0.27^{\mathrm{A}}$ & $7.55 \pm 0.36^{\mathrm{B}}$ \\
Overall acceptability & $8.50 \pm 0.21^{\mathrm{A}}$ & $7.85 \pm 0.34^{\mathrm{C}}$ & & $8.10 \pm 0.13^{\mathrm{B}}$ & $7.85 \pm 0.23^{\mathrm{C}}$ \\
\hline
\end{tabular}

All values are mean \pm SD.

${ }^{\mathrm{A}-\mathrm{C}}$ Means in the same row with different letters are significantly different $(p<0.05)$.

higher tenderness, juiciness, and overall acceptability score than those prepared using post-rigor muscle $(p<0.05)$. Hot-boned meat (pre-rigor muscle) was previously shown to having excellent sensory properties excluding flavor, especially in terms of tenderness and juiciness (Cross et al., 1979; Jacobs and Sebranek, 1980).

Therefore, the addition of soybean sauce to the Hanwoo patty prepared from pre-rigor muscle partially produced the beneficial effects of adding salt while simultaneously improving the sensory properties of the meat. The increase in cooking loss and reduction in diameter due to the higher tenderness and juiciness was not an issue in the sensory evaluation.

\section{Acknowledgements}

This paper was supported by Konkuk University in 2010 . The authors also were supported by the Brain Korean 21 (BK 21) Project from Ministry of Education and Human Resources Development.

\section{References}

1. Andersen, H. J., Bertelsen, G., and Skibsted, L. H. (1990) Colour and colour stability of hot processed frozen minced beef. Result from chemical model experiments tested under storage condition. Meat Sci. 28, 87-97.

2. Bernthal, P. H., Booren, A. M., and Gray, J. I. (1989) Effect of sodium chloride concentration on $\mathrm{pH}$, water-holding capacity and extractable protein of prerigor and postrigor ground beef. Meat Sci. 25, 143-154.

3. Berry, B. W., Bigner-George, M. E., and Eastridge, J. S. (1999) Hot processing and grind size affect properties of cooked beef patties. Meat Sci. 53, 37-43.

4. Boles, J. A. and Swan, J. E. (1997) Effects of brine ingredients and temperature on cook yields and tenderness of prerigor processed roast beef. Meat Sci. 45, 87-97.

5. Buckely, D. J., Gray, J. I., Asghar, A., Price, J. F., Krackel, R. L., Booren, A. M., Pearson, A. M., and Miller, E. R. (1989)
Effects of dietary antioxidants and oxidized oil on membrane lipid stability and pork product quality. J. Food Sci. 54, 1193-1197.

6. Choi, H. S., Lee, J. S., Moon, G. S., and Park, G. Y. (1990) Antioxidative characteristics of fermented soybean sauce on the oxidation of fatty acid mixture. Korean J. Food Sci. Technol. 22, 332-336.

7. Choi, J. H., Kim, I., Jeong, J. Y., Lee, E. S., Choi, Y. S., and Kim, C. J. (2009) Effects of carcass processing method and curing condition on quality characteristics of ground chicken breasts. Korean J. Food Sci. Ani. Resour. 29, 356-363.

8. Choi, K. S., Kim, Y. H., Yim, M. H., Choi, J. D., Jung, H. C., Kim, W. S., and Knon, K. Y. (2000) Effects of mashing proportion of soybean to salt brine on Kanjang (soy sauce) quality. Korean J. Food Sci. Technol. 32, 174-180.

9. Cross, H. R., Berry, B. W., and Muse, D. (1979) Sensory and cooking properties of ground beef prepared from hot and chilled beef carcasses. J. Food Sci. 44, 1432-1434.

10. Drerup, D. L., Judge, M. D., and Aberle, E. D. (1981) Sensory properties and lipid oxidation in pre-rigor processed fresh pork sausage. J. Food Sci. 46, 1659-1661.

11. Farouk, M. M. and Swan, J. E. (1997) Factors affecting protein functionality in frozen beef. Proceed. 43rd Int. Cong. Meat Sci. Technol., Auckland, New Zealand. pp. 388-389.

12. Farouk, M. M. and Swan, J. E. (1998) Effect of muscle condition before freezing and simulated chemical changes during frozen storage on the $\mathrm{pH}$ and colour of beef. Meat Sci. 50, 245-256.

13. Hamm, R. (1977) Postmortem breakdown of ATP and glycogen in ground muscle: A review. Meat Sci. 1, 15-39.

14. Hamm, R. (1981) Developments in Meat Science 2. Lawrie, R. (ed) Applied Science Publishers, London, England, p. 93.

15. Jabobs, D. K. and Sebranek, J. G. (1980) Use of prerigor beef for frozen ground beef patties. J. Food Sci. 45, 648-651.

16. Jeon, M. S., Sohn, K. H., Chae, S. H., Park, H. K., and Jeon, H. J. (2002) Color characteristics of Korean traditional soy sauces prepared under different processing conditions. $J$. Korean Soc. Food Sci. Nutr. 31, 32-38.

17. Jeremiah, L. E., Martin, A. H., and Murray, A. C. (1985) The effects of various post-mortem treatments on certain physical and sensory properties of three different bovine muscles. Meat Sci. 12, 155-176. 
18. Jones, M. L., Ray, E. E., Thomas, J. D., and Tsao, H. M. (1986) Effects of electrical stimulation, hot-boning and mixing vs tumbling on the physical and chemical properties of beef logs. J. Food Sci. 51, 1-4.

19. Kim, D. H., Jo, C., Yook, H. S., Park, B. J., and Byun, M. W. (2002) Enhancement of preservation characteristics of Meju, and intermediate material for Korean legume-based fermented soy sauce, Kanjang, by irradiation. Radiat. Phys. Chem. 64, 317-322.

20. Lamkey, J. W., Mandigo, R. W., and Calkins, C. R. (1986) Effect of salt and phosphate on the texture and color stability of restructured beef steaks. J. Food Sci. 51, 873-875.

21. Lawrie, R. A. (1998) Lawrie's meat science. 6th ed, Woodhead Publishing Ltd., Cambridge, England, pp. 69-72.

22. Lee, S. K., Mei, L., and Decker, E. A. (1997) Influence of sodium chloride on antioxidant enzyme activity and lipid oxidation in frozen ground pork. Meat Sci. 46, 349-355.

23. Moon, G. S. and Cheigh, H. S. (1986) Antioxidative effect of soybean sauce on the lipid oxidation of cooked meat. Korean J. Food Sci. Technol. 18, 313-318.

24. Pisula, A. and Tyburcy, A. (1996) Hot processing of meat. Meat Sci. 43, S125-S134.

25. Plimpton JR., R. F., Perkins, C. J., Sefton, T. L., Cahill, V. R., and Ockerman, H. W. (1991) Rigor condition, tumbling and salt level influence on physical, chemical and quality characteristics of cured, boneless hams. J. Food Sci. 56, 1514-1518.

26. Rashid, N. H., Henrickson, R. L., Asghar, A., and Claypool, P. L. (1983) Biochemical and quality characteristics of ovine muscles as affected by electrical stimulation, hot boning, and mode of chilling. J. Food Sci. 48, 136-140.

27. Rees, M. P., Trout, G. R., and Warner, R. D. (2002) Effect of calcium infusion on tenderness and ageing rate of pork $m$. longissimus thoracis et lumborum after accelerated boning. Meat Sci. 61, 169-179.

28. SAS. (1999) SAS/STAT Software for PC. Release 8.1, SAS
Institute Inc., Cary, NC, USA.

29. Seideman, S. C., Koohmaraie, M., and Crouse, J. D. (1987) Factors associated with tenderness in young beef. Meat Sci. 20, 281-291.

30. Shim, S. L., Ryo, K. Y., Kim, W., Jun, S. N., Seo, H. Y., Han, K. J., Kim, J. H., Song, H. P., Cho, N. C., and Kim, K. S. (2008) Physicochemical characteristics of medicinal herbs Ganjang. Korean J. Food Preserv. 15, 243-252.

31. Shin, H. K., Abugroun, H. A., Forrest, J. C., Okos, M. R., and Judge, M. D. (1999) Effect of heating rate on palatability and associated properties of pre- and postrigor muscle. $J$. Anim. Sci. 71, 939-945.

32. Silva, T. J. P., Orcutt, M. W., Forrest, J. C., Bracker, C. E., and Judge, M. D. (1993) Effect of heating rate on shortening, ultrastructure, and fracture behavior of prerigor beef muscle. Meat Sci. 33, 1-24.

33. Tarladgis, B. G., Watts, B. M., Younathanm, M. T., and Dugan, L. (1960) A distillation method for the quantitative determination of malonaldehyde in rancid foods. J. Am. Oil Chem. Soc. 37, 44-52.

34. Thomas, R., Anjaneyulu, A. S. R., and Kondaiah, N. (2008) Effect of hot-boned pork on the quality of hurdle treated pork sausages during ambient temperature $\left(37 \pm 1^{\circ} \mathrm{C}\right)$ storage. Food Chem. 107, 804-812.

35. Torres, E., Pearson, A. M., Gray, J. I., Booren, A. M., and Shimokomaki, M. (1988) Effect of salt on oxidative changes in pre- and post-rigor ground beef. Meat Sci. 23, 151-163.

36. Trout, G. R. (1988) Techniques for measuring water-binding capacity in muscle foods-A review of methodology. Meat Sci. 23, 235-252.

37. Young, O. A., Humphrey, S. M., and Wild, D. J. C. (1988) Effects of sugars on post-mortem glycolysis in bovine muscle mice. Meat Sci. 23, 211-225.

(Received 2010.7.17/Revised 2010.12.9/Accepted 2010.12.16) 